\title{
Erratum to: Fish habitat use response to anthropogenic induced changes of physical processes in the Elwha estuary, Washington, USA
}

\author{
J. Ann Shaffer $\cdot$ M. Beirne $\cdot$ T. Ritchie $\cdot$ \\ R. Paradis $\cdot$ D. Barry $\cdot$ P. Crain
}

Published online: 30 October 2012

(C) Springer Science+Business Media B.V. 2012

\section{Erratum to: Hydrobiologia (2009) 636:179-190 DOI 10.1007/s10750-009-9947-x}

Due to an unfortunate mistake, an incorrect version of Fig. 1 has been used in the original publication.
Asterisks indicating the sample sites did not show. The correct image and its caption is published on the following page and should be treated as definitive by the reader.

The online version of the original article can be found under doi:10.1007/s10750-009-9947-x.

\section{J. A. Shaffer $(\bowtie) \cdot$ T. Ritchie}

Washington Department of Fish and Wildlife, 332 E. 5th Street, Port Angeles, WA 98362, USA

e-mail: anne.shaffer@dfw.wa.gov

M. Beirne

Lower Elwha Klallam Tribe, Fish Hatchery Road,

Port Angeles, WA 98362, USA

e-mail: matt.beirne@elwha.nsn.us

R. Paradis · D. Barry

Western Washington University, Huxley College of the Environment, Port Angeles, WA 98362, USA

e-mail: Rebecca@clallambroadband.com

D. Barry

e-mail: dwight.barry@wwu.edu

P. Crain

Olympic National Park, 600 Park Avenue, Port Angeles,

WA 98362, USA

e-mail: Patrick_crain@nps.gov 


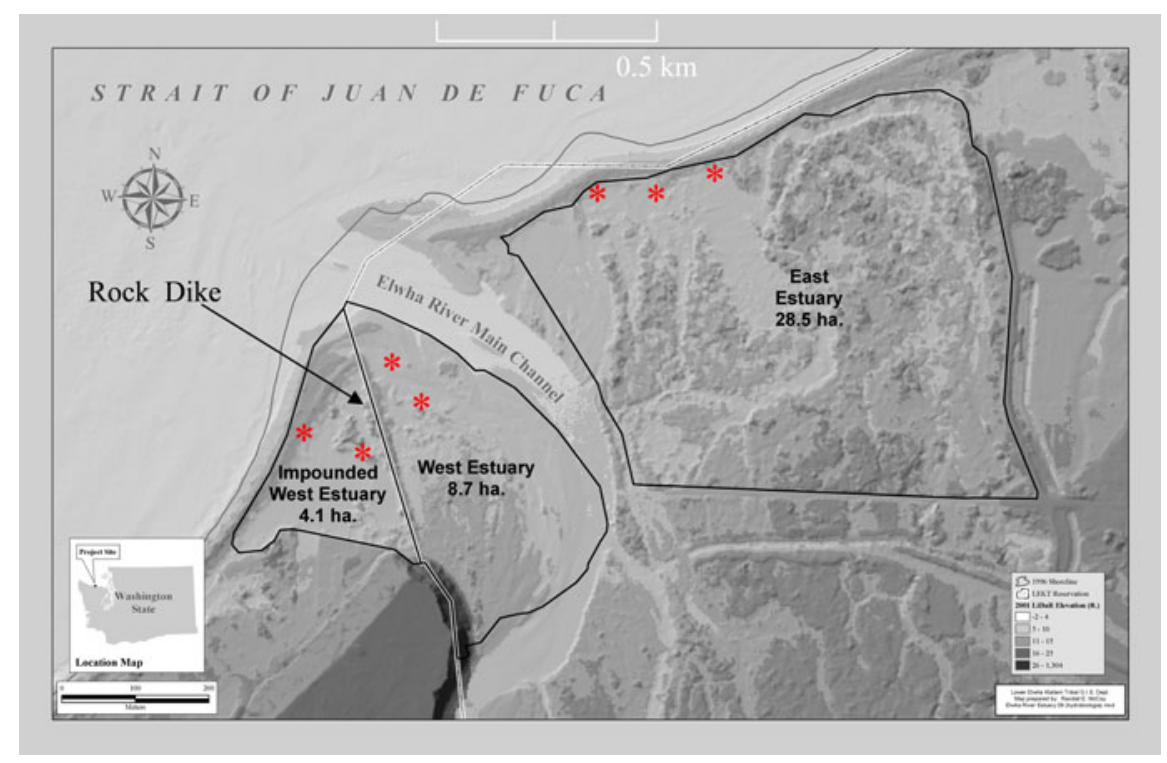

Fig. 1 Map of the Elwha Estuary with elevational profile and the three sampling areas delineated. Asterisks indicate sample sites 